\title{
An Accurate Computation of Block Hybrid Method for Solving Stiff Ordinary Differential Equations
}

\author{
Abdu Sagir Masanawa \\ Department of Basic Studies.College of Basic and Remedial Studies, Hassan Usman Katsina Polytechnic, \\ Katsina. Nigeria.
}

\begin{abstract}
In this paper, self-starting block hybrid method of order $(5,5,5,5)^{T}$ is proposed for the solution of the special second order ordinary differential equations with associated initial or boundary conditions. The continuous hybrid formulations enable us to differentiate and evaluate at some grids and off - grid points to obtain four discrete schemes, which were used in block form for parallel or sequential solutions of the problems. The computational burden and computer time wastage involved in the usual reduction of second order problem into system of first order equations are avoided by this approach. Furthermore, a stability analysis and efficiency of the block method are tested on stiff ordinary differential equations, and the results obtained compared favourably with the exact solution.
\end{abstract}

Keywords: Block Method, Hybrid, Linear Multistep Method, Self-starting, Special Second Order

\section{a. Introduction}

Let us consider the numerical solution of the special second order ordinary differential equation of the form

$$
y^{\prime \prime}=f(x, y), \quad a \leq x \leq b
$$

with associated initial or boundary conditions. The mathematical models of most physical phenomena especially in mechanical systems without dissipation leads to special second order initial value problem of type (1). Solutions to initial value problem of type (1) according to Fatunla [1,2] are often highly oscillatory in nature and thus, severely restrict the mesh size of the conventional linear multistep method. Such system often occurs in mechanical systems without dissipation, satellite tracking and celestial mechanics.

Lambert [3] and several authors such as Onumanyi et al [4], Awoyemi [5], Yahaya and Adegboye [6], and Fudziah et al. [7], have written on conventional linear multistep method

$\sum_{\mathrm{j}=0}^{\mathrm{k}} \propto_{\mathrm{j}} \mathrm{y}_{\mathrm{n}+\mathrm{j}}=\mathrm{h}^{2} \sum_{\mathrm{j}=0}^{\mathrm{k}} \beta_{\mathrm{j}} \mathrm{f}_{\mathrm{n}+\mathrm{j}}, \mathrm{k} \geq 2$

or compactly in the form

$\rho(E) y_{n}=\mathrm{h}^{2} \delta(E) \mathrm{f}_{\mathrm{n}}$

where $E$ is the shift operator specified by $E^{\mathrm{j}} y_{\mathrm{n}}=y_{\mathrm{n}+\mathrm{j}}$ while $\rho$ and $\delta$ are characteristics polynomials and are given as

$$
\rho(\xi)=\sum_{j=0}^{\mathrm{k}} \alpha_{\mathrm{j}} \xi^{\mathrm{j}}, \delta(\xi)=\sum_{\mathrm{j}=0}^{\mathrm{k}} \beta_{\mathrm{j}} \xi^{\mathrm{j}}
$$

$\mathrm{y}_{\mathrm{n}}$ is the numerical approximation to the theoretical solution $\mathrm{y}(\mathrm{x})$ and $\mathrm{f}_{\mathrm{n}}=\mathrm{f}\left(\mathrm{x}_{\mathrm{n}}, \mathrm{y}_{\mathrm{n}}\right)$.

In the present consideration, our motivations for the study of this approach is a further advancement in efficiency, i.e obtaining the most accuracy per unit of computational effort, that can be secured with the group of methods proposed in this paper over Taparki and Odekunle [9] and Adeboye [8], and.

\subsection{Definition : Consistent Lambert [3]}

The linear multistep method (2) is said to be consistent if it has order $p \geq 1$, that is, if

$$
\sum_{\mathrm{j}=0}^{\mathrm{k}} \alpha_{\mathrm{j}}=0 \text { and } \sum_{\mathrm{j}=0}^{\mathrm{k}} \mathrm{j} \alpha_{\mathrm{j}}-\sum_{\mathrm{j}=0}^{\mathrm{k}} \beta_{\mathrm{j}}=0
$$

Introducing the first and second characteristics polynomials (4), we have from (5) LMM type (2) is consistent if $\rho(1)=0, \rho^{1}(1)=\delta(1)$

\subsection{Definition: Zero stability Lambert [3]}

A linear multistep method type (2) is zero stable provided the roots $\xi_{\mathrm{j}}, \mathrm{j}=0(1) \mathrm{k}$ of first characteristics polynomial $\rho(\xi)$ specified as $\rho(\xi)=\operatorname{det}\left|\sum_{j=0}^{\mathrm{k}} \mathrm{A}(\mathrm{i}) \xi^{(\mathrm{k}-\mathrm{i})}\right|=0$ satisfies $\left|\xi_{\mathrm{j}}\right| \leq 1$ and for those roots with $\left|\xi_{\mathrm{j}}\right|=1$ the multiciplicity must not exceed two. The principal root of $\rho(\xi)$ is denoted by $\xi_{1}=\xi_{2}=1$.

\subsection{Definition: Convergence Lambert [3]}

The necessary and sufficient conditions for the linear multistep method type (2) is said to be convergent if it is consistent and zero stable. 
1.4 Definition: Order and Error Constant Lambert [3]

The linear multistep method type (2) is said to be of order $\mathrm{p}$ if $\mathrm{c}_{0}=\mathrm{c}_{1}=\cdots \mathrm{c}_{\mathrm{P}+1}=0$

but $\mathrm{c}_{\mathrm{p}+2} \neq 0$ and $\mathrm{c}_{\mathrm{p}+2}$ is called the error constant,

where $\mathrm{c}_{0}=\sum_{\mathrm{j}=0}^{\mathrm{k}} \propto_{\mathrm{j}}=\propto_{0}+\propto_{1}+\propto_{2}+\ldots+\propto_{\mathrm{k}}$

$$
\begin{aligned}
\mathrm{c}_{1} & =\sum_{\mathrm{j}=0}^{\mathrm{k}} \mathrm{j} \propto_{\mathrm{j}}=\left(\propto_{1}+2 \propto_{2}+3 \propto_{3}+\ldots+\mathrm{k} \propto_{\mathrm{k}}\right)-\left(\beta_{0}+\beta_{1}+\beta_{2}+\cdots+\beta_{\mathrm{k}}\right) \\
\mathrm{c}_{2} & =\sum_{\mathrm{j}=0}^{\mathrm{k}} \frac{1}{2 !} \mathrm{j}^{2} \alpha_{\mathrm{j}}-\sum_{\mathrm{j}=0}^{\mathrm{k}} \beta_{\mathrm{j}} \\
& =\left\{\frac{1}{2 !}\left(\propto_{1}+2^{2} \propto_{2}+3^{3} \propto_{3}+\ldots+\mathrm{k}^{2} \propto_{\mathrm{k}}\right)-\left(\beta_{1}+2 \beta_{2}+3 \beta_{3}+\ldots+\mathrm{k} \beta_{\mathrm{k}}\right)\right\} \\
\cdot & \\
\mathrm{c}_{\mathrm{q}} & =\sum_{\mathrm{j}=1}^{\mathrm{k}}\left\{\frac{1}{\mathrm{q} !} \mathrm{j}^{\mathrm{q}} \propto_{\mathrm{j}}-\frac{1}{(\mathrm{q}-2) !} \mathrm{j}^{\mathrm{q}-2} \beta_{\mathrm{j}}\right\} \\
& =\left\{\frac{1}{q !}\left(\propto_{1}+2^{\mathrm{q}} \propto_{2}+3^{\mathrm{q}} \propto_{3}+\ldots+\mathrm{k}^{\mathrm{q}} \propto_{\mathrm{k}}\right)-\frac{1}{(\mathrm{q}-1) !}\left(\beta_{1}+2^{(\mathrm{q}-1)} \beta_{2}+3^{(\mathrm{q}-1)} \beta_{3}+\cdots+\mathrm{k}^{(\mathrm{q}-1)} \beta_{\mathrm{k}}\right)\right\}
\end{aligned}
$$

\subsection{Theorem: Lambert [3]}

Let $\mathrm{f}(\mathrm{x}, \mathrm{y})$ be defined and continuous for all points $(\mathrm{x}, \mathrm{y})$ in the region $D$ defined by $\{(\mathrm{x}, \mathrm{y}): \mathrm{a} \leq \mathrm{x} \leq \mathrm{b},-\infty<\mathrm{y}<$ $\infty$ \} where a and $\mathrm{b}$ finite, and let there exist a constant $L$ such that for every $x, y, y^{*}$ such that $(x, y)$ and $\left(x, y^{*}\right)$ are both in $D$ :

$\left|f(x, y)-f\left(x, y^{*}\right)\right| \leq L|y-y *|$

Then if $\eta$ is any given number, there exist a unique solution $y(x)$ of the initial value problem (1), where $y(x)$ is continuous and differentiable for all $(x, y)$ in $D$. The inequality (7) is known as a Lipschitz condition and the constant $L$ as a Lipschitz constant.

Consequently, this paper is organized as follows: in first section we will show the introduction, this lead to second section which shows how the method was derived, third section presents stability analysis of the method with some numerical experiments, while the forth and last section of this paper concludes the work and references respectively.

\section{Derivation Of The Proposed Method}

We proposed an approximate solution to (1.1) in the form

$\mathrm{y}(\mathrm{x})=\sum_{\mathrm{j}=0}^{\mathrm{t}+\mathrm{m}-1} \mathrm{a}_{\mathrm{j}} \mathrm{x}^{\mathrm{i}}=\mathrm{y}_{\mathrm{n}+\mathrm{j}}, \mathrm{i}=0(1) \mathrm{m}+\mathrm{t}-1$

$\mathrm{y}^{\prime \prime}(\mathrm{x})=\sum_{\mathrm{j}=0}^{\mathrm{t}+\mathrm{m}-1} \mathrm{i}(\mathrm{i}-1) \mathrm{a}_{\mathrm{j}} \mathrm{x}^{\mathrm{i}-2}=\mathrm{f}_{\mathrm{n}+\mathrm{j}}, \mathrm{i}=2(3) \mathrm{m}+\mathrm{t}-1$

with $\mathrm{m}=5, \mathrm{t}=2$ and $\mathrm{p}=\mathrm{m}+\mathrm{t}-1$

where the $a_{j}, j=0,1,(m+t-1)$ are the parameters to be determined, $t$ and $m$ are points of interpolation and collocation respectively. Where $P$, is the degree of the polynomial interpolant of our choice.

Specifically, we collocate equation (9) at $\mathrm{x}=\mathrm{x}_{\mathrm{n}+\mathrm{j}}, \mathrm{j}=0(1) \mathrm{k}$ and interpolate equation (8) at $\mathrm{x}=\mathrm{x}_{\mathrm{n}+\mathrm{j}}$, $\mathrm{j}=0(1) \mathrm{k}-2$ using the method described above. Putting in the matrix equation form and then solved to obtain the values of parameters $\alpha_{j}, j=0,1, \ldots$ which is substituted in (8) yields, after some algebraic manipulation, the new continuous form for the solution

$y(x)=\sum_{j=0}^{k-2} \alpha_{j}(x) y_{n+j}+\sum_{j=0}^{k} \beta_{j}(x) f_{n+j}$

We set $\xi=\left(\mathrm{x}-\mathrm{x}_{\mathrm{n}+1}\right)$

If we let $\mathrm{k}=3$, after some algebraic manipulations we obtain a continuous form of solution

$$
\begin{aligned}
& \mathrm{y}(\mathrm{x})=\{-(\xi)\} \mathrm{y}_{\mathrm{n}}+\left\{\left(\frac{\mathrm{h}+\xi}{\mathrm{h}}\right)\right\} \mathrm{y}_{\mathrm{n}+1} \\
& +\left\{\frac{6(\xi)^{6}-30 \mathrm{~h}(\xi)^{5}+45 \mathrm{~h}^{2}(\xi)^{4}-20 \mathrm{~h}^{3}(\xi)^{3}+101 \mathrm{~h}^{5}(\xi)}{1440 \mathrm{~h}^{4}}\right\} \mathrm{f}_{\mathrm{n}} \\
& +\left\{\frac{-6(\xi)^{6}+21 \mathrm{~h}(\xi)^{5}+5 \mathrm{~h}^{2}(\xi)^{4}-70 \mathrm{~h}^{3}(\xi)^{3}+60 \mathrm{~h}^{4}(\xi)^{2}+108 \mathrm{~h}^{5}(\xi)}{120 \mathrm{~h}^{4}}\right\} \mathrm{f}_{\mathrm{n}+1} \\
& +\left\{\frac{-6(\xi)^{6}+12 \mathrm{~h}(\xi)^{5}+25 \mathrm{~h}^{2}(\xi)^{4}-20 \mathrm{~h}^{3}(\xi)^{3}+27 \mathrm{~h}^{5}(\xi)}{240 \mathrm{~h}^{4}}\right\} \mathrm{f}_{\mathrm{n}+2} \\
& +\left\{\frac{54(\xi)^{6}-162 \mathrm{~h}(\xi)^{5}-135 \mathrm{~h}^{2}(\xi)^{4}+540 \mathrm{~h}^{3}(\xi)^{3}-459 \mathrm{~h}^{5}(\xi}{800 \mathrm{~h}^{4}}\right\} \mathrm{f}_{\mathrm{n}+\frac{4}{3}} \\
& +\left\{\frac{6(\xi)^{6}-3 \mathrm{~h}(\xi)^{5}-15 \mathrm{~h}^{2}(\xi)^{4}+10 \mathrm{~h}^{3}(\xi)^{3}-16 \mathrm{~h}^{5}(\xi)}{1800 \mathrm{~h}^{4}}\right\} \mathrm{f}_{\mathrm{n}+3}
\end{aligned}
$$


Evaluating equation (11) at $\mathrm{x}=\mathrm{x}_{\mathrm{n}+4 / 3}, \mathrm{x}=\mathrm{x}_{\mathrm{n}+2}$ and $\mathrm{x}=\mathrm{x}_{\mathrm{n}+3}$, yield the following schemes:
(a) $y_{n+\frac{4}{3}}-\frac{4}{3} y_{n+1}+\frac{1}{3} y_{n}=\frac{h^{2}}{437400}\left\{10135 f_{n}+146580 f_{n+1}+15690 f_{n+2}-73953 f_{n+4 / 3}-1252 f_{n+3}\right\}$
(b) $\mathrm{y}_{\mathrm{n}+2}-2 \mathrm{y}_{\mathrm{n}+1}+\mathrm{y}_{\mathrm{n}}=\frac{\mathrm{h}^{2}}{1200}\left\{85 \mathrm{f}_{\mathrm{n}}+1180 \mathrm{f}_{\mathrm{n}+1}+190 \mathrm{f}_{\mathrm{n}+2}-243 \mathrm{f}_{\mathrm{n}+4 / 3}-12 \mathrm{f}_{\mathrm{n}+3}\right\}$
(c) $y_{n+3}-3 y_{n+1}+2 y_{n}=\frac{h^{2}}{1200}\left\{155 f_{n}+2640 f_{n+1}+1470 f_{n+2}-729 f_{n+\frac{4}{3}}+64 f_{n+3}\right\}$

Taking the first derivative of equation (11), thereafter, evaluate the resulting continuous polynomial solution at $\mathrm{x}=\mathrm{x}_{0}$ yields

(d) $h z_{0}-y_{n+1}+y_{n}=\frac{h^{2}}{7200}\left\{-1625 f_{n}-6060 f_{n+1}-1110 f_{n+2}+5103 f_{n+\frac{4}{3}}+92 f_{n+3}\right\}$

Equations (12) and (13) constitute the member of a zero stable block integrators of order $(5,5,5,5)^{\mathrm{T}}$ with $c_{7}=\left(\frac{2351}{3936600}, \frac{7}{3600}, \frac{1}{600},-\frac{143}{50400}\right)$. The application of the block integrators with $\mathrm{n}=0$ gives the accurate values of unknown as shown in tables 1 and 2 of forth section of this paper.

To start the IVP integration on the sub interval $\left[X_{0}, X_{3}\right]$, we combine equations (12) and (13), when $\mathrm{n}=0$ i.e the 1-block 4-point method are given in equation (14). Thus produces simultaneously values for $\mathrm{y}_{1}, \mathrm{y}_{2}, \mathrm{y}_{3}$ and $\mathrm{y}_{\frac{4}{3}}$

\section{Stability Analysis}

Recall, that, it is a desirable property for a numerical integrator to produce solution that behave similar to the theoretical solution to a problem at all times. Thus, several definitions, which call for the method to posses some "adequate" region of absolute stability, can be found in several literatures. See Lambert [3], Fatunla [1,2] e.t.c

Following Fatunla [1,2], the four integrator proposed in this report in equation (12) and (13) are put in the matrix equation form and for easy analysis the result was normalized to obtain;

$\left[\begin{array}{llll}1 & 0 & 0 & 0 \\ 0 & 1 & 0 & 0 \\ 0 & 0 & 1 & 0 \\ 0 & 0 & 0 & 1\end{array}\right]\left[\begin{array}{l}y_{n+1} \\ y_{n+\frac{4}{3}} \\ y_{n+2} \\ y_{n+3}\end{array}\right]=\left[\begin{array}{cccc}0 & 0 & -\frac{1}{3} & 1 \\ 0 & 0 & -1 & 3 \\ 0 & 0 & -2 & 6 \\ 0 & 0 & -1 & 3\end{array}\right]\left[\begin{array}{c}y_{n-2} \\ y_{n-\frac{5}{3}} \\ y_{n-1} \\ y_{n}\end{array}\right]+h^{2}\left\{\left[\begin{array}{cccc}-\frac{913}{5400} & \frac{523}{14580} & -\frac{313}{109350} & -\frac{14}{81} \\ -\frac{81}{400} & \frac{19}{120} & -\frac{1}{100} & -1 \\ -\frac{243}{400} & \frac{49}{40} & \frac{4}{75} & -4 \\ \frac{567}{800} & -\frac{37}{240} & \frac{23}{1800} & \frac{1}{6}\end{array}\right]\left[\begin{array}{c}f_{n+1} \\ f_{n+\frac{4}{3}} \\ f_{n+2} \\ f_{n+3}\end{array}\right]+\left[\begin{array}{cccc}0 & 0 & 0 & \frac{2027}{87480} \\ 0 & 0 & 0 & \frac{17}{240} \\ 0 & 0 & 0 & \frac{31}{240} \\ 0 & 0 & 0 & -\frac{65}{288}\end{array}\right]\left[\begin{array}{c}f_{n-2} \\ f_{n-\frac{5}{3}} \\ f_{n-1} \\ f_{n}\end{array}\right]\right\}$

with $\mathrm{y}_{0}=\left(\begin{array}{c}\mathrm{y}_{0} \\ \mathrm{hz}\end{array}\right)$ usually giving along the initial value problem. Equation (14) is the 1- block 4 - point method.

The first characteristics polynomial of the proposed 1 - block 4 - point method is given by

$$
\begin{aligned}
& \rho(\lambda)=\operatorname{det}\left[\lambda I-A_{1}^{(1)}\right] \\
& \rho(\lambda)=\operatorname{det}\left[\begin{array}{cccc}
\lambda & 0 & \frac{1}{3} & -1 \\
0 & \lambda & 1 & -3 \\
0 & 0 & \lambda+2 & -6 \\
0 & 0 & 1 & \lambda-3
\end{array}\right]
\end{aligned}
$$

Solving the determinant of equation (13), yields

$\rho(\lambda)=\lambda^{3}(\lambda-1)$, which implies, $\lambda_{1}=\lambda_{2}=\lambda_{3}=0$ or $\lambda_{4}=1$

By definition of zero stable and equation (16), the 1 - block 4 - point method is zero stable and is also consistent as its order $(5,5,5,5)^{\mathrm{T}}>1$, thus, it is convergent following Henrici [10] and Fatunla [2].

\section{Numerical Experiments}

In what follows, we present some numerical results on some problems.

Problem 1: Consider the IVP $y^{\prime \prime}=y, x \in[0,1], y_{0}=1, y_{0}^{\prime}=1, h=0.1$, whose exact solution is $y=e^{x}$ 
TABLE 1: Results for the Proposed Method

\begin{tabular}{|c|c|c|c|c|}
\hline $\mathrm{x}$ & Exact Solution & $\begin{array}{c}\text { Approximate } \\
\text { Value }\end{array}$ & $\begin{array}{c}\text { Error of Proposed } \\
\text { Method }\end{array}$ & $\begin{array}{c}\text { Taparki and Qdekunle. } \\
\text { [9] }\end{array}$ \\
\hline 0.1 & 1.105170918 & 1.105170918 & $0.0000 \mathrm{E}+00$ & $4.920292 \times 10^{-3}$ \\
\hline 0.2 & 1.221402758 & 1.221402758 & $0.0000 \mathrm{E}+00$ & $2.037513 \times 10^{-2}$ \\
\hline 0.3 & 1.349858808 & 1.349858807 & $5.7600 \mathrm{E}-10$ & $4.7477416 \times 10^{-2}$ \\
\hline 0.4 & 1.491824698 & 1.491824696 & $1.6413 \mathrm{E}-09$ & $8.7788535 \times 10^{-2}$ \\
\hline 0.5 & 1.648721271 & 1.648721269 & $1.7001 \mathrm{E}-09$ & $1.4235215 \times 10^{-1}$ \\
\hline 0.6 & 1.822118800 & 1.822118798 & $2.3905 \mathrm{E}-09$ & $2.1268728 \times 10^{-1}$ \\
\hline 0.7 & 2.013752707 & 2.013752704 & $3.4705 \mathrm{E}-09$ & $3.0047789 \times 10^{-1}$ \\
\hline 0.8 & 2.225540928 & 2.225540924 & $4.4925 \mathrm{E}-09$ & $4.07590071 \times 10^{-1}$ \\
\hline 0.9 & 2.459603111 & 2.459603107 & $4.1569 \mathrm{E}-09$ & $5.3609119 \times 10^{-1}$ \\
\hline 1.0 & 2.718281828 & 2.718281824 & $4.4590 \mathrm{E}-09$ & $6.88271136 \times 10^{-1}$ \\
\hline
\end{tabular}

Problem 2: Consider the Bup $y^{\prime \prime}-\mathrm{y}=4 \mathrm{x}-5 ; \mathrm{y}(0)=\mathrm{y}(1)=0, \mathrm{~h}=0.1$, whose exact solution is $y=\frac{7}{4\left(e^{2}-e^{-2)}\right.}\left[e^{2 x}-e^{-2 x}\right]-\frac{3}{4} x$

TABLE 2: Results for the Proposed Method

\begin{tabular}{|c|c|c|c|c|}
\hline $\mathrm{x}$ & Exact Solution & $\begin{array}{c}\text { Approximate } \\
\text { Value }\end{array}$ & $\begin{array}{c}\text { Error of Proposed } \\
\text { Method }\end{array}$ & Aclebexe [8] \\
\hline 0.0 & 0.00000000000 & 0.0000000000 & $0.000000000 \mathrm{E}+00$ & $0.000000000 \mathrm{E}+00$ \\
\hline 0.1 & 0.14735784232 & 0.1473578284 & $1.390000000 \mathrm{E}-08$ & $6.598600000 \mathrm{E}-06$ \\
\hline 0.2 & 0.25015214537 & 0.2501521164 & $2.890000000 \mathrm{E}-08$ & $9.454000000 \mathrm{E}-06$ \\
\hline 0.4 & 0.31341504348 & 0.3134150000 & $4.340000000 \mathrm{E}-08$ & $1.156300000 \mathrm{E}-05$ \\
\hline 0.5 & 0.34178302747 & 0.3417825591 & $4.680000000 \mathrm{E}-07$ & $1.204180000 \mathrm{E}-05$ \\
\hline 0.6 & 0.33954334810 & 0.3395424500 & $8.981000000 \mathrm{E}-07$ & $8.902600000 \mathrm{E}-06$ \\
\hline 0.7 & 0.25889818576 & 0.2588965200 & $1.665700000 \mathrm{E}-06$ & $2.803580000 \mathrm{E}-05$ \\
\hline 0.9 & 0.18769224781 & 0.1876902363 & $2.011500000 \mathrm{E}-06$ & $8.259870000 \mathrm{E}-05$ \\
\hline 1.0 & 0.10034979197 & 0.1003474152 & $2.376700000 \mathrm{E}-06$ & $1.870490000 \mathrm{E}-04$ \\
\hline
\end{tabular}

V.

Conclusion

In this paper, a new block method with uniform integrators of order $(5,5,5,5)^{\mathrm{T}}$ was developed. The resultant numerical integrators posses the following desirable properties:

i. Zero stability i.e. stability at the origin

ii. Convergent schemes

iii. An addition of equation from the use of first derivative

iv. Being self - starting as such it eliminate the use of predictor - corrector method

v. Facility to generate solutions at 4 points simultaneously

vi. Produce solution over sub intervals that do not overlaps

vii. Apply uniformly to both $\mathrm{IVP}_{\mathrm{s}}$ and $\mathrm{BVP}_{\mathrm{s}}$ with adjustment to the boundary conditions

In addition, the new schemes compares favourably with the theoretical solution and the results are more accurate than Taparki and Odekunle [9], and Adeboye [8], see table 1 and 2 respectively. Hence, our work is an improvement over other cited works.

\section{References}

[1] S.O. Fatunla, Block Method for Second Order Initial Value Problem. International Journal of Computer Mathematics, England. Vol. 4, 1991, pp $55-63$.

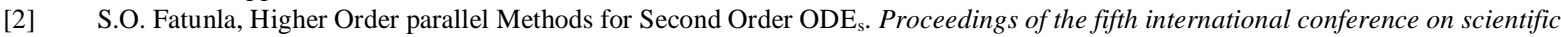
computing, 1994, pp $61-67$.

[3] J.D.Lambert, Computational Methods in Ordinary Differential Equations (John Willey and Sons, New York, USA, 1973)

[4] P. Onumanyi, D.O. Awoyemi, S.N. Jator and U.W. Sirisena, New linear Multistep with Continuous Coefficient for first order initial value problems. Journal of Mathematical Society, 13, 1994, pp 37 - 51

[5] D.O. Awoyemi, A class of Continuous Stormer - Cowell Type Methods for Special Second Order Ordinary Differential Equations. Journal of Nigerian Mathematical Society Vol. 5, Nos. 1 \& 2, 1998, pp100 - 108

[6] Y.A. Yahaya and Z.A. Adegboye, A family of 4 - step Block Methods for Special Second Order in Ordinary Differential Equations. Proceedings Mathematical Association of Nigeria, 2008, pp $23-32$.

[7] I. Fudziah L. K. Yap. and O. Mohammad, Explicit and Implicit 3 - point Block Methods for Solving Special Second Order Ordinary Differential Equations Directly. International Journal of math. Analysis, Vol. 3, 2009, pp 239 - 254.

[8] K.R. Adeboye, A superconvergent $\mathrm{H}^{2}-$ Galerkin method for the solution of Boundary Value Problems. Proceedings National Mathematical Centre, Abuja, Nigeria. Vol. 1 no.1, 2000, pp 118 - 124, ISBN 978 - 35488 - 0 - 2

[9] R. Taparki and M.R. Odekunle, An Implicit Runge - Kutta Method for Second Order Initial Value Problem in Ordinary Differential Equations. International Journal Num. Mathematics, Vol. 5 No. 2, 2010, pp 222 - 234

[10] P. Henrici, Discrete Variable Methods for ODE . (John Willey New York U.S.A, 1962) 